\title{
ANALISA PERILAKU KONSUMEN DAN NILAI KOMIK JEPANG
}

\author{
DJUDIYAH \\ Jurusan Psikologi Fakultas Psikologi Universitas Muhammadiyah Malang \\ E-mail: Djudiyahdahlan@yahoo.com
}

\begin{abstract}
ABSTRAK
Penelitian ini bertujuan untuk menganalisa dan menjelaskan motivasi dan macam-macam nilai dari Komik Jepang. Metode yang digunakan untuk penelitian ini adalah penelitian kuantitatif. Subyek pada penelitian adalah 35 siswa Sekolah Menengah Pertama di Malang, dimana digunakan teknik sampling insidental. Instrumen untuk mengumpulkan data adalah kuesioner. Metode analisa data adalah deskriptif kuantitatif. Hasil pertama dari penelitian ini adalah faktor motivasinya adalah kebutuhan sosial, kebutuhan egoistik, aktualisasi diri dan kebutuhan rasa aman. Kedua, nilai dari komik jepang adalah gambar dan bahasa yang digunakan dalam komik jepang mudah dimengerti, topiknya bervariasi dan kebanyakan sama dengan budaya Indonesia dan kadang ceritanya lebih realistik dan harganya lebih murah dibanding komik Amerika.
\end{abstract}

Kata kunci: perilaku konsumen, nilai, komik jepang

\begin{abstract}
This research was aimed to analysis and described motivations and kinds of consumer values Japanese comics. The methods used in this research is quantitative research. The subject in this research is 35 students State Yunior High School in Malang, which is using incidental sampling techniques. The instrument to collect the data is questionare. The data analysis methods is quantitaive descriptive. The first result of the research are the motivating factor is social needs, egoistic needs, self actualization and safety needs. The second, the values Japanese comics is the picture and the language used in the Japanese comics are more understandable, the topic is varieties and almost the same with Indonesian culture ever it is more realistic storys and the cost is cheaper than American comics.
\end{abstract}

Key word: consumen behaviour, values, japanese comic

\section{PENDAHULUAN}

Kebutuhan konsumen akan mendorong dan mengarahkan individu untuk bertindak. Kondisi semacam ini disebut dengan motivasi. Motivasi digambarkan sebagai dorongan yang sangat kuat dalam diri individu untuk bertindak. Dorongan yang sangat kuat ini muncul karena adanya kondisi ketegangan (tension) yang ada sebagai hasil karena kebutuhan yang tidak terpenuhi. Individu baik secara sadar maupun tidak sadar akan mengurangi tension melalui perilaku yang mereka antisipasi untuk memenuhi kebutuhan mereka sehingga terbebas dari perasaan tertekan (Schiffman dan Kanuk, 2000). Solomon (1996) menyatakan bahwa motivasi menunjuk pada proses yang menyebabkan orang bertindak sebagaimana yang telah dilakukan. Hal ini terjadi ketika kebutuhan muncul karena konsumen ingin memperoleh kepuasan. Sekali kebutuhan aktif, keadaan tension akan muncul yang mendorong konsumen untuk berusaha mengurangi atau mengeleminir kebutuhan. Pemasar berusaha untuk menciptakan produk dan jasa yang dapat memenuhi keinginan konsumen yang menguntungkan dan sesuai dengan kebutuhan untuk mengurangi tension.

Menurut Maslow (dalam Schiffman dan Kanuk, 2000) ada lima kebutuhan dasar manusia yaitu, kebutuhan fisik (physiological needs), kebutuhan rasa aman (safety needs), kebutuhan sosial (social needs), kebutuhan egoistik (egoistic or esteem needs) serta kebutuhan akan aktualisasi diri (self-actualization) dalam membeli produk atau jasa. Ada kalanya konsumen membeli produk atau jasa didorong oleh kebutuhan fisik. Misalnya: orang merasa haus maka ia akan membeli Aqua. Adakalanya konsumen menabung uangnya di bank karena ingin memperoleh rasa aman dari pencuri. Adakalanya konsumen memilih baju model yang sedang tren karena takut dianggap kuno oleh temantemannya. Ada kalanya konsumen membeli produk tertentu karena ingin mendapatkan penghargaan dari orang lain serta adakalanya konsumen membeli 
buku untuk memenuhi kebutuhan aktualisasi diri, dan lain-lain. Oleh karena itu, produk atau jasa yang dapat memenuhi kebutuhan konsumenlah yang akan laku dipasaran, dapat membuat konsumen puas dan akan loyal terhadap produk atau jasa.

Nilai atau value juga merupakan aspek penting yang dapat membuat konsumen puas serta loyal atau setia terhadap produk atau jasa. Nilai atau value diartikan sebagai selisih antara nilai pelanggan total dan biaya pelanggan total. Nilai pelanggan total merupakan sekumpulan manfaat yang diharapkan oleh pelanggan dari produk atau jasa tertentu. Biaya total pelanggan adalah sekumpulan biaya yang diharapkan oleh konsumen yang dikeluarkan untuk mengevaluasi, mendapatkan, menggunakan dan membuang produk atau jasa (Kotler, 2000). Dengan demikian dapat dikatakan bahwa produk atau jasa yang memberikan nilai lebih akan membuat konsumen puas dan dapat membuat konsumen loyal terhadap produk atau jasa. Salah satu alasan mengapa komik menjadi populer akhir-akhir ini adalah karena pengaruh TV (Johannsson dan Nonka, 1998). TV dianggap sebagai media gambar yang utama (Schiffman dan Kanuk, 2000) yang dapat berpengaruh pada perilaku konsumen. Acaraacara TV banyak menayangkan film-film kartun yang banyak digemari anak-anak maupun remaja, Misalnya Shinchan, Samurai X dan Spongebob. Cerita yang ada di film-film kartun ini juga banyak kesamaan atau kemiripan dengan cerita-cerita yang ada di komik, khususnya komik Jepang sehingga anak-anak juga suka membaca komik Jepang.

Menurut Polay, et al. (1996) ada beberapa alasan mengapa sensitivitas advertensi lebih berpengaruh pada anak-anak muda bila dibandingkan dengan orang dewasa, salah satu alasan tersebut adalah pembentukan identitas dan perhatian advertensi pada remaja adalah untuk membentuk identitas diri, yang menyebabkan remaja yang berumur belasan memperhatikan pengaruh advertensi dan peergroupnya terhadap cue yang berhubungan dengan simbol-simbol kedewasaan dan penerimaan orang lain. Remaja belasan juga lebih mampu menerima image yang romantis, sukses, mengagumkan, popular dan adventurir, dimana hal ini akan dicapai dengan cara mengkonsumsi rokok. Ditambahkan oleh Loudon dan Bitta bahwa remaja belasan, banyak mengalami ketidak menentuan dan menyebabkan mereka ingin untuk menemukan indentitas dirinya. Mereka akan aktif mencari cue dari peernya dan dari advertensi sebelum mereka berperilaku. Mereka menjadi tertarik pada bermacam-macam produk yang dapat mengekspresikan kebutuhan mereka untuk eksperimen, belonging, independent, bertanggung jawab dan disukai orang lain (Solomon, 1999).
Editor komik PT. Indira Publishing yang mengungkapkan bahwa kehadiran komik-komik Jepang seperti: Doraemon, Kungfu Boy ataupun Sailor Moon ternyata mampu mengalihkan perhatian anak-anak dari komik asing lain seperti Tin-tin atau Lucky Luke (Republika, 24 Agustus, 1997). Anakanak menjadi lebih menyukai komik Jepang dari pada komik-komik asing lainnya. Demikian besar konsumen komik Jepang ini, sehingga sebuah majalah anak-anak yang cukup populerpun harus memuat komik Jepang agar laku (Kompas, 5 Pebruari 1998). Komik Jepang pada akhirnya merajalela. Setiap hari selalu ada saja pengunjung yang menekuni rak-rak komik di toko Buku Gramedia Malang yang nyaris semua berasal dari Jepang. Sementara banyak anak dan remaja lain yang dengan setia pergi ke perpustakaan atau taman-taman bacaan terdekat untuk membaca komik Jepang tersebut. Hal ini tidak saja terjadi di Indonesia, menurut Koh (1999) remaja belasan di bangkok, Singapore, dan negara-negara lain banyak mengkoleksi komik Jepang. Kenyataan ini menimbulkan pentanyaan, mengapa anak-anak dan remaja sangat menyukai komik Jepang bila dibandingkan dengan komik yang berasal dari Eropa, Amerika maupun dari Indonesia sendiri (lokal).

\section{METODE}

Penelitian ini merupakan penelitian kuantitatif. Penelitian ini dimaksudkan untuk mengetahui motivasi serta nilai (value) lebih yang dipersepsikan dan dirasakan oleh remaja ketika mereka menyewa, membaca, membeli ataupun mengkoleksi komik Jepang. Populasi dalam penelitian ini adalah siswa SLTP yang menjadi pelanggan persewaan komik "Tumapel Agency" di Singosari Malang. Sampel penelitian ini berjumlah 35 orang yang diambil dengan teknik Incidental Sampling. Metode pengumpul data yang digunakan dalam penelitian ini adalah kuesioner. Teknik analisis data yang digunakan dalam penelitian ini adalah deskriptif kuantitatif.

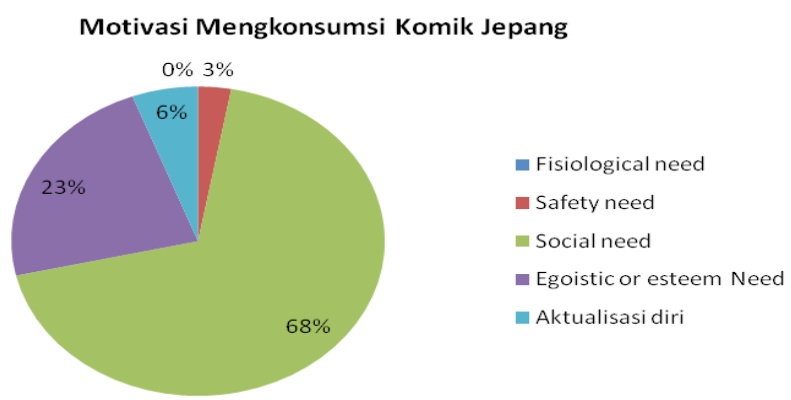

Gambar 1. Motivasi Mengkonsumsi Komik Jepang 
Hasil analisis data menunjukkan bahwa dari 35 siswa SLTP yang menjadi responden dalam penelitian ini, ada 24 siswa (68\%) yang mengkonsumsi komik Jepang untuk memenuhi kebutuhan sosial (social need), ada 8 siswa (23\%) untuk memenuhi kebutuhan egoistik atau esteem need, ada 2 siswa (6\%) untuk memenuhi kebutuhan aktualisasi diri serta ada 1 siswa (3\%) untuk memenuhi kebutuhan rasa aman (safety need).

\section{Value/Nilai Komik Jepang}

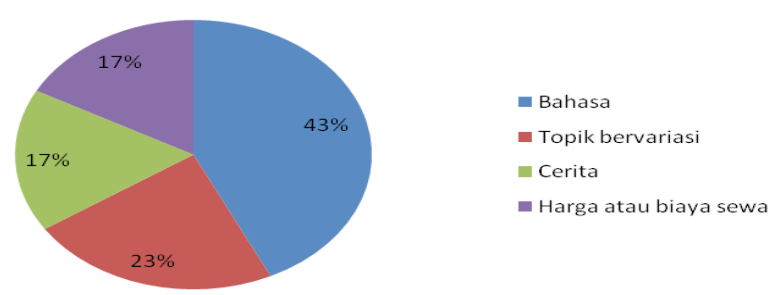

Gambar 2. Value Komik Jepang

Hasil analisis data juga menunjukkan bahwa ada 15 siswa (43\%) yang mengatakan bahwa gambar maupun bahasa yang disajikan mudah dicerna atau pahami, ada 8 siswa (23\%) yang beranggapan bahwa topik yang ditawarkan lebih bervariasi, topik yang ditawarkan tidak jauh berbeda dengan dongeng ataupun cerita yang ada di Indonesia, topik yang ditawarkan sesuai dengan perkembangan jiwa segment pasarnya, topik yang ditawarkan tidak ada muatan politis. Ada 6 siswa (17\%) menyatakan bahwa cerita yang ditawarkan lebih realistis atau menyentuh kehidupan sehari hari serta ada 6 siswa (17\%) siswa yang mengatakan bahwa harga beli maupun ongkos pinjam maupu harga beli di toko buku lebih murah komik Jepang di banding dengan komik dari Amerika.

\section{HASIL DAN PEMBAHASAN}

Hasil analisis data menemukan bahwa motivasi siswa mengkonsumsi komik Jepang adalah untuk memenuhi kebutuhan sosial (social needs). Hal ini sesuai dengan tugas perkembangan remaja adalah mampu menjalin hubungan interpersonal dengan orang-orang disekitarnya. Hubungan interpersonal ini merupakan sarana bagi remaja untuk menemukan jati diri atau identitas diri remaja (Hurlock, 1992). Komik dapat dijadikan topik pembicaraan yang sangat menarik bagi remaja, apalagi jika remaja memiliki kesamaan topik komik yang dibacanya. Hal ini akan membuat hubungan interpersonal diantara mereka akan semakin erat karena memiliki kesukaan yang sama (Feldman, 1999).
Penelitian ini juga menemukan bahwa remaja mengkonsumsi komik Jepang didorong oleh keinginan untuk mendapatkan penghargaan dari teman-temannya. Remaja akan berlomba-lomba untuk menemukan topik-topik komik yang terbaru dan berusaha membacanya. Mereka akan merasa bangga ketika menemukan topik bacaan yang temantemannya belum pernah membacanya. Temuan ini memperkuat hasil penelitian yang dilakukan Suprawanti (1999) bahwa siswa yang suka membaca komik Jepang ternyata memiliki motivasi berprestasi yang tinggi dibanding dengan siswa yang tidak suka membaca komik Jepang.

Hasil analisis data juga menemukan bahwa gambar maupun bahasa yang ada pada komik Jepang lebih mudah dipahami atau di cerna dibanding komik yang berasal dari Amerika. Hal ini sesuai dengan perkembangan kognitif anak-anak yang sedang pada masa transisi dari konkrit operasional ke formal operasional (Feldman, 1999). Pada masa ini anakanak sudah mampu berfikir secara abstrak, formal dan logis. Pada saat ini anak mulai berfikir tanpa mengobservasi lingkungan dalam waktu lama namun masih menggunakan teknik-teknik yang logis dalam penyelesaian masalah.

Hasil penelitian juga menemukan bahwa topik cerita yang ada pada komik Jepang sangat bervariasi. Misalnya: tentang olah raga, percintaan, persahabatan, dan lain lain. Hal ini sesuai dengan pendapatnya Izawa (1998) bahwa aspek cerita pada komik barat terlihat jauh dari realitas kehidupan sehari-hari. Komik Barat cenderung hanya menyentuh sedikit realitas nyata proporsi terbanyak lebih pada cerita-cerita fantasi. Sedangkan komik Jepang cenderung menggabungkan antara cerita fantasi dengan realitas kehidupan sehari-hari seperti orang biasa, mereka pergi kesekolah, mengerjakan pekerjaan rumah, dimarahi orang tua, tetapi mereka juga memiliki kehidupan lain yang membuat mereka berbeda dengan orang biasa, entah karena bakat yang luar biasa atau karena memiliki teman yang aneh. Malahan ada juga komik Jepang dengan cerita yang sangat nyata, yang menggambarkan kehidupan sehari-hari seorang remaja. Misalnya: jatuh cinta, ujian, sekolah persahabatan, dan lain sebagainya.

Penelitian ini juga menemukan bahwa cerita yang dimuat di komik Jepang hampir sama dengan dongeng atau cerita yang ada di Indonesia. Misalnya ada tokoh-tokoh jahat (Bawang Merah, Malinkundang, dan lain-lain), ada tokoh-tokoh yang baik (bawang putih, cinderela, dan lain-lain). Hal ini sesuai dengan paparan Izawa (1998) bahwa tokoh pada komik-komik Barat seringkali memiliki karakter yang terpilah menjadi dua, yaitu tokoh 
antagonis yang digambarkan begitu jahat dan tokoh protagonis yang sebaliknya dilukiskan sangat baik dan hebat. Sedangkan pada komik-komik Jepang, karakter tokoh-tokohnya tidak begitu saja terbagi menjadi hitam dan putih. Seringkali digambarkan sang lakon melakukan kesalahan yang tak mungkin terjadi pada tokoh utama komik Barat, dan sang musuh memiliki alasan-alasan kejahatannya yang bisa membuat pembaca bersimpati. Tokoh antagonis pada komik Jepang ditunjukkan tidak begitu saja jahat atau gila tetapi tokoh-tokoh ini juga memiliki harapan dan mimpinya sendiri.

Hal ini berarti bahwa nilai (value) budaya Jepang memiliki beberapa kesamaan dengan budaya Indonesia. Hal ini sesuai dengan pendapat Schiffman \& Kanuk (2000) bahwa kebudayaan merupakan salah satu faktor yang sangat berpengaruh pada perilaku konsumen. Nilai-nilai budaya konsumen yang sama dengan sesuatu yang ada produk merupakan faktor yang dapat mempengaruhi konsumen dalam proses keputusan membeli sesuatu.

Cerita yang ada pada komik Jepang sesuai dengan perkembangan jiwa anak remaja serta menyentuh kehidupan sehari- hari, misalnya: tentang percintaan, persahabatan. Hal ini sesuai dengan pendapat Hurlock(1992) yang menyatakan bahwa saat memasuki masa remaja, anak akan mengalami perkembangan dan pertumbuhan yang pesat baik secara fisik, psikologis maupun sosial. Pertumbuhan dan perkembangan yang sangat pesat ini sangat berpengaruh pada atensi maupun minat terhadap produk yang mereka konsumsi.

Menurut Hurlock (1992) salah satu cara untuk mencoba mengangkat diri sendiri sebagai individu adalah dengan menggunakan simbol status dalam bentuk mobil, pakaian, dan pemilikan barangbarang lain yang mudah terlihat. Dengan cara ini remaja menarik perhatian pada diri sendiri dan agar dipandang sebagai individu, sementara pada saat yang sama ia mempertahankan identitas dirinya terhadap kelompok sebaya. Penerimaan diri sendiri maupun penerimaan atau dukungan sosial terutama geng merupakan sesuatu yang penting dalam kebahagiaan remaja.

Monks, Knoers dan Haditono (2000) menyatakan bahwa remaja akan lebih mementingkan perannya sebagai anggota kelompok dari pada mengembangkan pola norma sendiri. Moral kelompok tadi dapat berbeda sekali dengan moral yang dibawa remaja dari keluarga yang sudah lebih dihayatinya karena sudah sejak keil diajarkan oleh orang tua. Sementara itu Riesman dan de hass (dalam Monks, Knoers dan Haditono, 2000) menyatakan bahwa orang menilai konformisme kelompok ini positif sebagai bantuan menemukan identitas diri.
Pada penelitian ini ditemukan juga bahwa harga sewa maupun harga beli komik Jepang ternyata lebih murah dibanding dengan komik Amerika. Hal ini di dukung oleh pendapatnya Schiffman \& Kanuk (2000) yang menyatakan bahwa konsumen adakalanya memiliki motivasi yang sifatnya rasional saat membeli sesuatu dimana salah satunya dengan mempertimbangkan atau membandingkan antara harga dengan sesuatu yang hendak didapatkannya.

\section{SIMPULAN}

Perilaku siswa membaca komik Jepang dimotivasi oleh keinginan untuk memenuhi kebutuhan sosial atau kebutuhan untuk diterima oleh teman-temannya terutama peer groupnya, kebutuhan egoistik atau kebutuhan untuk mendapatkan penghargaan, kebutuhan aktualisasi diri serta kebutuhan akan rasa aman dari teman-temannya. Value lebih yang dimiliki oleh komik Jepang adalah gambar maupun bahasa yang disajikan mudah di cerna. Topik yang ditawarkan lebih bervariasi dan tidak jauh berbeda dengan dogeng ataupun cerita yang ada di Indonesia. Selain itu, topik yang ditawarkan sesuai dengan perkembangan jiwa segment pasarnya dan tidak ada muatan politis. Value yang cerita yang ditawarkan lebih realistis atau menyentuh kehidupan sehari hari, harga beli maupun ongkos pinjam lebih murah. Value yang lebih dari komik Jepang mendorong dan memotivasi konsumen untuk membeli dan membaca komik Jepang.

\section{DAFTAR PUSTAKA}

Atkinson, R dan Flint, J. 2001. http: www.soc.surrey.ac.uk/ sru/SRU33.html

Armando, A., darojah, S. dan Sugianti, R. 1997. Komik Nasional, Bangkit, Mati Lagi. Kalau saja koran dan majalah memberi tempat, kelemahan komik nasional: cerita. Republika. 24 Agustus 1997, hal. 3.

Bonneff, N. 1998. Komik Indonesia. Jakarta: Kepustakaan Populer Gramedia.

Feldman, R. S. 1999. Understanding Psychology. Fifth Edition. Toronto: McGraw-Hill College.

Hadi, S. 2001. Metodologi Riset. Jilid 1 dan 2. Yogyakarta: Andi Offset.

Hidayat, R. S. 1998. Mempertanyakan komik (di) Indonesia. Kompas. 5 Pebruari 1998, hal. 19.

Hurlock, E.B. 1992. Psikologi Perkembangan. Suatu Pendekatan Sepanjang Rentang kehidupan. Edisi Kelima. Jakarta: Erlangga.

Imai, M. 1996. KAIZEN (Kunci Sukses Jepang Dalam Persaingan). Jakarta: PT Pustaka Binaman Pressindo.

Izawa, E. 1998. (Via Internet)

Johansson, J.K dan Nonaka, I. 1998. Cara Pemasaran Ala Jepang. Jakarta: PT Gramedia Pustaka Utama. 
Kim, J., Lim, J and Bhargava. 1998. The Role of Affect in Attitude Formation: A Classical Conditioning Approach. Journal of Academy of marketing Science. Vol. 26, No: 2, pages 143-152.

Koh, B. 1999. Cute Power (society and the Arts). Newsweek, November 8, 1999.

Kotler, P. dan Amstrong, G. 1998. Principles of Marketing (Dasar-dasar Pemasaran). Jilid 2. Jakarta: Prehallindo.

Kotler, P. 2000. Manajemen Pemasaran. Edisi Milenium. Jilid 1. Jakarta: Prenhallindo

Mc. Cutchen. 1991. Comic Books, The Newbook of Knowledge. Connecticut: Grolier, Inc.

Monks, F.J. Knoers, A.M.P., dan Haditono, S.R. 2000. Psikologi Perkembangan. Pengantar Dalam Berbagai Bagiannya. Yogyakarta: Gadjah Mada University Press.

Petri, Herbert L. 1981. Motivation: Theory and Research. USA: Wadworth, Inc.

Poerwadarminta, W.J.S. 1997. Kamus Umum Bahasa Indonesia. Jakarta: PN Balai Pustaka.
Pollay, R.W., Siddarth, S., Siegel, M., Haddix, A., Merrit, R. K., Giovino, G.A. and Erikson, M.P. 1996. Journal of Marketing. Vol. 60. April 1996, 1-16.

Power and Kato.1989. Handbook of Japanese Popular Culture. Usa: Greenwood Press, Inc.

Rahman, A. 1989. Rahasia japan Inc. Menyingkap Habis Siasat Bisnis Jepang dalam Perang Dagang dengan Amerika. Jakarta: Indomedia.

Schiffman, L.G. And Kanuk, L.L. 2000. Consumer Behavior. USA: Prentice Hall International, Inc.

Sekaran, U. 2000. Research Method for Bussiness. A Skill Building Approach. Third Edition. USA: John Willey and Sons, Inc.

Solomon, M.R. 1999. Consumer Behavior. Buying, Having and Being. Third Edition. USA: Prentice Hall International, Inc.

Sudjana, N. dan Rivai, A. 1997. Media Pengajaran (Penggunaan dan Pembuatannya). Bandung: CV Sinar Baru.

Suprawati, M.M.N.E. 1999. Motif Berprestasi pada Pembaca Komik Jepang di SMP dan SMU. Skripsi (tidak diterbitkan). Yogyakarta: Fakultas Psikologi UGM. 